\title{
Pain warrior
}

Cite as: CMAJ 2019 April 15;191:E425-6. doi: 10.1503/cmaj.180957

CMAJ Podcasts: audio reading at https://soundcloud.com/cmajpodcasts/180957-enc

isa sat hunched over in the office chair, her skin pale against the black leather. A red neoprene allergy mask covered most of her face, and watery blue eyes peered out from above the barrier. "Careful," she said, as she offered an outstretched, paper-thin hand.

A psychiatrist had referred Lisa to me after she was recently admitted to our local hospital. There was no way I could resist our community psychiatrist's kind brown eyes and huge smile, but l'd begun to regret my decision to accept Lisa as a patient. Bottles of controlled-release hydromorphone 12-mg capsules, hydromorphone tablets and zopiclone tablets glared at me through amber plastic. Captain Enthusiastic could feel her ship Optimistic take on water. I sighed, dreading the task ahead.

The provincial college of physicians and surgeons had introduced new opioid prescribing regulations. I ignored their first letter, confident I was an underprescriber of the potentially lethal substances. Poor deluded doc. Months later, reams of computer printout had revealed the ugly truth - a long list of patients flagged for my attention. Lisa threatened to scupper my mission to slash the list.

Lisa looked at least a decade older than her 56 years, her body bent over and fragile. She'd left an abusive partner to live with fellow church members. She said, "The last few years with them felt like a living hell." The couple exploited her and she'd become increasingly withdrawn and isolated. Her brother lived in our community, and she had relocated to live with him.

A week after her discharge from hospital, during our first office visit, she requested an increase in her opioid dosage. She had pain everywhere, from the

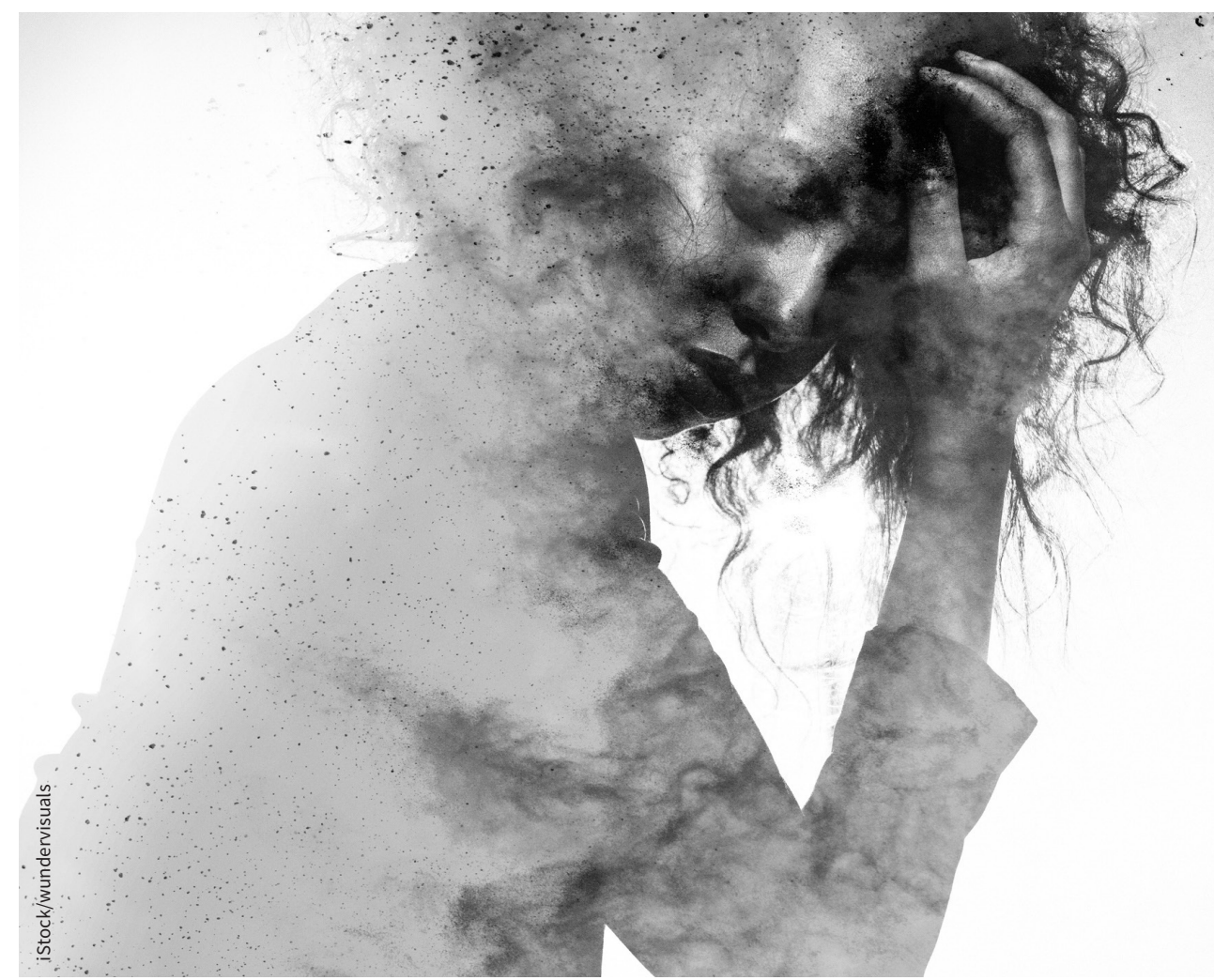

top of her head to her bilateral bunions. Previous doctors had said she had fibromyalgia. Lisa couldn't recall having had any major injuries to account for her pain.

The idea of prescribing Lisa opioids for fibromyalgia and mechanical back pain made me anxious. As I explained the dangers of combining long- and shortacting opioids with hypnotics, her eyes widened. I ended our visit with the assurance I wouldn't make any drastic changes to her medications. We'd work together, at her pace. This promise made me distinctly uncomfortable.

How was I supposed to manage Lisa's pain without adding to her stress and causing her incredible suffering, while adhering to the new practice standard from the college? Without multidisciplinary pain clinics available to patients in our community, undertreatment of pain in my practice had become all too common.

Initially I made no changes to her medications, but screaming pain drove her to the emergency department. I scheduled weekly appointments. Lisa would hobble into the office, crumpled over a cane, wheezing through her neoprene mask. Investigations were unhelpful and referrals to the university pain clinic and a regional back clinic were returned to the office with notes that they were unable to help.

The mental health team from our regional hospital worked their supratentorial magic. Within a year after Lisa's first 
hospital admission, a social worker helped her find her own apartment. She received home and community supports and was referred to a provincial selfmanagement program.

I fought to help Lisa understand her pain, focusing on the role of fascia. My instructions that she stretch and move were met with looks that varied from incredulous to what-the-hell-do-youknow. My agenda to wean her from opioids completely was at odds with her reality.

Lisa landed back in hospital, unable to move from back pain. I went back to the pain strategies I had learned from provincial resources for family physicians. I gave her a simple modification of one of the recovery poses and told her to use it every five minutes if necessary. I reminded her of abdominal breathing. Three days later she walked out, in pain, but with two tools that seemed to help, along with a smidgen of hope.

Hope was something that had been in short supply in Lisa's life. From a young age she'd been sexually abused by a family member, and later by her father. Soon after the sexual abuse began, her periods started, along with pelvic pain. Many of her memories lay deeply buried and she said, "I existed in a fog."

Pain had become the central force in her life and allowed her no room to think, plan, dream or pray. Over the following four months, with the help of nurses, her psychiatrist, church members, social workers and provincial self-management programs, which included weekly telephone coaching, Lisa improved exponentially. She no longer feared stretching and walking. Best of all, she no longer feared pain.

Twelve months since her last hospital discharge, Lisa is doing well on $6 \mathrm{mg}$ of controlled-release hydromorphone. In the past three years, she has required only a couple of short courses of hydromorphone for foot and kidney-stone surgeries. She hasn't used zopiclone for more than three years.

As Lisa's pain subsided, church meetings and interactions with members of her congregation became possible. Lisa said, "I started to feel there was some use for me. I know I can't run a marathon, but I can pick the phone up and speak to someone. Help them feel better."

Lisa bought a small dog and her cane was replaced by a leash. She no longer exists in sympathetic overdrive. Without wild fluctuations in adrenaline, noradrenaline, cortisol and other inadvertently villainous neuro-hormones, her inflammation has decreased. Her wheezes have disappeared, as has her mask. She is now a confident woman with shining blue eyes, who looks her age, and she can accept a hug, or a handshake, without cringing in pain.

Lisa's confidence in managing her pain mirrored my own journey. Rather than adhering blindly to unrealistic demands, I mindfully listen to my patients and consider the full story.
In order to provide my patients with as much information as possible about pain and all the available resources, I approached our local rural division of family practice. The divisions in our province are committees run by family physicians. Provincial incentive funding is provided for initiatives that hope to have a positive effect on community health. This local division provided me with funding and I created a website (www.painimprovement.com) that helps to reduce the time I needed to spend in the office reviewing available resources that are helpful to my patients with chronic pain. I hope it will prove helpful to other physicians and patients.

Our four-year journey has helped me find a better approach to managing chronic pain, and I have realized that the pain warriors in my practice deserve to be heard. They have a lot to teach us.

\section{Judy Dercksen MBBCh MpraxMed \\ Quesnel, BC}

This article has been peer reviewed.

This is a true story. Lisa has given her consent for this story to be told. Details have been changed to protect her identity.

Acknowledgements: Without the support from my own staff, allied health care professionals at our regional hospital, our local psychiatrist, the provincial self-management program, family doctors who took over my duties in the emergency room - freeing up time for me to research and work on chronic pain - I would never have managed the process. I thank them all. 